\title{
Pedagogía del Ser en Educación Infantil: una propuesta desde el álbum ilustrado
}

Leonor Ruiz Guerreroruiz_leonor@hotmail.com

Universidad de Murcia, España

Reference

Guerrero, Leonor Ruíz; (2012) "Pedagogía del Ser en Educación Infantil: una propuesta desde el álbum ilustrado", p. 113-118. In: Barbosa, Helena; Quental, Joana [Eds]. Proceedings of the 2nd International Conference of Art, Illustration and Visual Culture in Infant and Primary Education. São Paulo: Blucher, 2015

ISSN 2318-695X, ISBN: 978-989-98185-0-7

DOI 10.5151/edupro-aivcipe-23

La construcción de la identidad es un tema al que debe darse preferencia en las aulas de Educación Infantil, enfocándola tanto en su 7aceta individual como colectiva. Si analizamos la cultura visual, específicamente la de los medios de masas, que rodea al alumnado de esta etapa educativa, convendremos en que no proporciona un modelo válido para la construcción de dichas identidades. Es por tanto preciso buscarlo en otras fuentes. Desde esta comunicación se propone hacerlo en el campo del álbum ilustrado, centrándonos en la colección Pomelo de Ramona Badescu y Benjamin Chaud. A través de ella se conducirá al alumnado a la reflexión sobre su propia identidad, y a la comunicación con los demás para descubrir las claves de la identidad común. Consideramos que este proceso de descubrimiento provocará en los niños una motivación hacia un mayor autoconocimiento.

Abstract

The constructon of identity is a very important issue in Infant Education, and it must be focused on both individual and collective identity. If we analyse visual culture, especially that of mass media, which surrounds our students, we must agree that it does not give a proper model for the construction of those identities. So we need to look for this model in other sources. In this paper we propose to use the picture book, in particular Pomelo collection by Ramona Badescu and Benjamin Chaud. Through these books, we will lead the students to think about their own identity, and talk to others in order to discover the keys of common identity. We think this discovering process may motivate children to do a better self- knowledge.

Infant Education, individual and collective identity, picture book.

\section{Introducción}

La cuestión de la identidad parece a menudo demasiado compleja para trabajarla en Educación Infantil, pero es necesario hacerlo, por su influencia determinante en la vida futura de los/as estudiantes. La construcción de una identidad clara y positiva, diferenciada de otras identidades, permitirá al pupilo/a desenvolverse con autonomía y seguridad en su entorno inmediato. Una identidad definida que no supone, por otro lado, desgajar al individuo de la sociedad en que se inserta, sino, al contrario, supone la asunción de que son las singularidades las que forman la pluralidad.

Del mismo modo, no podemos obviar que ya desde el Informe Delors (Delors, 1996:91-103) se alude al Aprender a Ser como uno de los cuatro pilares básicos de la educación.

Tema que ya fue tratado con anterioridad por la UNESCO, y que ha sido revisitado por gran diversidad de autores, como Ken Robinson (RTVE, 2011), en la actualidad. 
$2^{\text {nd }}$ International Conference Art, Illustration and Visual Culture in Infant and Primary Education
Congresso Internacional

de Arte, llustracão e Cultura Visual

na Educação Infantil e Primária

Tras observar que en la cultura visual que envuelve a los niños, muy especialmente la proveniente de los mass media, los planteamientos son en su mayoría alienantes y poco proclives a la creación de una identidad única y positiva, además de promover escasamente el sentimiento de pertenencia a una comunidad, iniciamos la búsqueda de un verdadero modelo que pudiera ser trasladado a las aulas.

Y lo encontramos en el mundo del álbum ilustrado, y más concretamente en la colección Pomelo de Ramona Badescu y Benjamin Chaud, publicada por la editorial Kókinos.

Este material literario, gracias a su riqueza textual e icónica, va a hacer posible la reflexión personal sobre todas las dimensiones que conforman la identidad, así como la puesta en común para llegar a una deliberación más amplia sobre la comunidad de esas dimensiones.

De ese modo, en esta comunicación lo que se pretende es hacer una propuesta para tratar la cuestión de la identidad en la etapa educativa ya mencionada. Creemos firmemente que es posible plantear esta cuestión en las aulas de Infantil, y que el trabajo con estos álbumes ilustrados puede contribuir a ello.

\section{Pedagogía del Ser}

"El director (de una orquesta) no hace ningún sonido. Su poder depende de su habilidad de hacer poderosas a otras personas. [...] Me di cuenta de que mi trabajo era despertar posibilidades en otras personas". (Zander, 2008).

Esta cita del director de orquesta Benjamin Zander resume a la perfección en qué consiste la pedagogía del Ser. Cada persona encierra en sí misma una cantidad ingente de posibilidades, posibilidad de soñar, de relacionarse con otros, de sentirse feliz,... Todas ellas son las que la conforman, cuyo descubrimiento y desarrollo conlleva la creación de su identidad. Cuando conocemos nuestras posibilidades, nos convertimos en poderosos. Tomamos conciencia de que Somos, y eso se constituye en una fuerza que nos hace invencibles. La pedagogía del Ser trata, como bien dice Zander, de despertar posibilidades. Idea que encontramos también en Ken Robinson, cuando nos habla de destrezas:

El tercer gran objetivo de la educación es personal: lo saben los que tienen hijos pero también cualquiera que esté vivo: una de las cosas que esperamos de la educación es que nos ayude a convertirnos en la mejor versión de nosotros mismos; que nos ayude a descubrir nuestros talentos, nuestras destrezas. (Robinson, 2011).

Asunto que también fue tratado mucho antes, en 1972, en el informe de la Comisión Internacional para el Desarrollo de la Educación, publicado precisamente bajo el título Aprender a ser:

[...] La educación ya no se define en relación a un contenido determinado que se trata de asimilar, sino que se concibe, en su verdad, como un proceso del ser que, a través de la diversidad de sus experiencias, aprende a expresarse, a comunicar, a interrogar al mundo y a devenir cada vez más él mismo. (Faure et. al, 1973: 220)

A nosotros nos gusta hablar, en un sentido similar, de enigmas. Cada niño/a es un enigma por descifrar, y la educación tendría como objetivo ayudarle/a a descifrarlo. Poner al alcance del niño la comprensión de que el mejor descubrimiento posible es el de sí mismo.

Una vez definida de una forma algo somera lo que es la pedagogía de la que estamos hablando, debemos plantearnos si la cultura visual a la que tienen acceso los niños de Infantil les permite una elaboración adecuada de su identidad. Estamos inmersos en una cultura capitalista, dominada por los mercados, que requiere de individuos consumistas y productivos, y se encarga de crearlos por medio de los mass media. Hay unos estándares que no consienten al niño interrogarse o cuestionarlos, que ni siquiera exponen asuntos realmente cercanos al mundo infantil.

Esas imágenes se interiorizan y crean patrones de conducta. Se extienden poco a poco dando a entender que eso es lo correcto y deseable.

El enigma queda entonces obviado, irresoluto. Se ignora su carácter único y la obligación de tratarlo como tal. También se pasa por alto que todos los enigmas generan preguntas. Que 
2nd International Conference Art, Illustration and Visual Culture in Infant and Primary Education $2^{\circ}$ Congreso Internacional

Arte, llustración y Cultura Visual en Educación Infantil y Primaria
Congresso Internacional

de Arte, llustração e Cultura Visual

na Educação Infantil e Primária

\section{Propuesta desde el álbum ilustrado}

a pesar de su unicidad, las respuestas para descifrarlos parten de la resolución de enigmas similares.

La Pedagogía del Ser, después de lo visto, puede resultar tremendamente compleja, mas no por el término en sí, sino porque hace urgente la pausa, la observación, la pregunta, la narración, la escucha. Porque precisa de nuevos espejos en los que mirarse, en los que verse y ver a otros.

Ese nuevo espejo en el que mirarse, alternativo a los que ofrece la cultura visual imperante, lo hallamos en el territorio del álbum ilustrado, en la colección Pomelo.

El álbum ilustrado es un género literario en el que el lector se implica de forma cómplice con el texto y las imágenes. En la colección que presentamos hay un constante diálogo con el lector, con continuos guiños humorísticos, y a veces incluso con interpelación directa. La empatía que provoca este tipo de texto puede facilitar esa reflexión que deseamos sobre la propia experiencia, al asimilarla a la del protagonista.

Por otra parte, la elección de esta serie y no otra, tiene su justificación tanto en la temática tratada, como en las muy adecuadas ilustraciones que la acompañan. Éstas se imbrican con el texto, aportando nuevos significados, aclarando otros, etc. Los dibujos de Chaud son sencillos, fáciles de comprender y agradables a la vista por el empleo, en su mayoría, de colores cálidos. llustraciones a menudo irónicas, pensadas para un lector inteligente que sabrá interpretarlas. La empatía comentada antes se ve enfatizada por el tamaño y las expresiones del protagonista, humanizado, así como por la cotidianeidad de las situaciones que vive. Éstas se presentan bajo un nuevo prisma, convertidas en inesperadas y emocionantes aventuras, como si la vida, sin más, pudiera constituirse en el más interesante hallazgo.

Ya los títulos de la serie funcionan como preludio de lo que nos espera en el interior de cada libro, y nos dan las primeras claves de las dimensiones posibles a analizar. Así, encontramos: Pomelo sueña; Pomelo es elefantástico; Pomelo se pregunta; Pomelo es feliz; Pomelo viaja; Pomelo al otro lado del huerto; y Pomelo crece.

La colección está protagonizada, como indican todos los títulos, por Pomelo, que no es más que un pequeño elefante rosa. No obstante, al igual que ocurre con los niños, su tamaño no le impide interrogarse sobre grandes cuestiones. Sin embargo, lo que más nos interesa de este personaje es que sabe quién es (conoce sus posibilidades), aunque nunca de forma definitiva, y quiénes son los que lo rodean.

Por eso mismo, Pomelo puede ayudarnos como docentes a forjar la identidad de nuestro alumnado, a enseñarle a Ser.

Nuestra propuesta en el aula se va a estructurar en una doble vertiente: la reflexión individual de cada niño sobre las ideas expuestas en los álbumes, buscando puntos de conexión con ellas (construcción de la identidad personal, el Yo); y un segundo momento de reflexión colectiva, dirigiendo a los niños a la toma de conciencia sobre la presencia de puntos de vista distintos al propio, dispares pero en esencia comunes (construcción de la identidad grupal, los otros y Nosotros). Consiste en dar lugar a un tiempo de comunicación-comunión entre el niño lector y el texto, y entre todos los alumnos del aula. Citando a Fernández Martorell (2008: 155,156): "Cada uno se hace a sí mismo a través de la comunicación con los demás. Forma su carácter en el lazo afectivo y en la admiración, a través de la palabra portadora de la historia, mediante la cual cada uno irá tejiendo poco a poco su propia identidad."

Si nos centramos en los títulos de la serie, advertiremos que en cada uno de ellos podemos encontrar alguna de las dimensiones de la identidad. Veámoslo más detenidamente:

\section{Dimensión social:}

Esta dimensión está presente en Pomelo al otro lado del huerto, especialmente en el primer capítulo: Todos se burlan de Pomelo. A partir de él podemos hablar sobre la importancia de la amistad, sobre qué ocurre cuándo no nos sentimos apreciados o integrados dentro del grupo, qué sensaciones conlleva el que se rían de nosotros o nos ignoren, también de la inquietud que producen los cambios, y de la esperanza de nuevos encuentros. 
$2^{\text {nd }}$ International Conference Art, Illustration and Visual Culture in Infant and Primary Education
${ }^{\circ}$ Congreso Internacional

Arte, llustración y Cultura Visual en Educación Infantil y Primaria de Arte, llustração e Cultura Visual

na Educação Infantil e Primária
Por otra parte, es posible hallarla en Pomelo sueña y Pomelo viaja, en concreto en los capítulos Qué patata tan rara y La Patatita, respectivamente. Aquí podemos iniciar una conversación sobre las diferencias entre las personas, y sobre la búsqueda de aspectos compartidos que nos ayuden a crecer juntos y a reconocernos en los otros (llegando al Nosotros).

\section{Dimensión psicológica:}

Nos vamos a apoyar en los volúmenes Pomelo es feliz y Pomelo es elefantástico. El primero dará lugar al debate sobre qué nos gusta o no de nosotros, y de cómo convertir lo que parece un defecto en una virtud (aceptación de uno mismo). Podemos observarnos para conocer cómo somos, físicamente o de carácter, preguntando también a los demás cómo nos ven y cómo se ven.

Del mismo modo, con ese primer volumen, podemos tratar el tema de los miedos, que también nos conforman. Al igual que las cosas que nos hacen felices y las tristezas, estas últimas expuestas en Pomelo se pregunta.

En cuanto a Pomelo es elefantástico, su tercer capítulo nos va a ofrecer una oportunidad inmejorable para trabajar el autoconcepto positivo, facilitando a los/as alumnos/as el hallazgo de aquellas características que los hacen especiales. En este caso no se trata, como en los modelos que presentan los mass media, de tener superpoderes, sino de descubrir que el mayor superpoder posible es el de saber quién eres. A este respecto encontramos una idea similar en Pomelo crece, donde se plantean los cambios, también en lo relativo a la identidad, que conlleva el hecho de crecer.

Quizás de todos los volúmenes, el que más ampliamente y mejor trata el tema de la identidad sea Pomelo se pregunta. En él aparecen interrogantes tanto sobre la identidad individual como colectiva. Pomelo, al igual que los niños, suele ser egocéntrico, pero en esta ocasión también es capaz de ponerse en el lugar de otros. Se habla de la identidad en tanto aspecto físico, relaciones sociales, o lugar donde se vive.
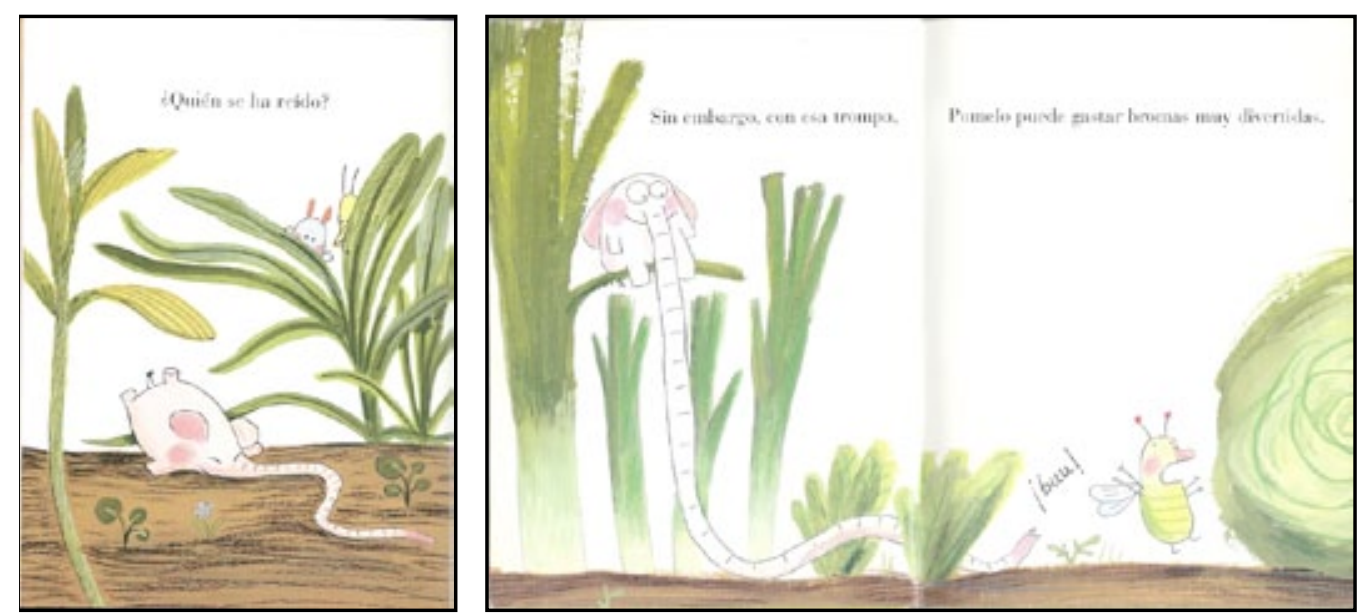

\section{Dimensión afectiva:}

Esta importante dimensión, ligada a la social y a la psicológica, ya que todas están interrelacionadas, puede ser trasladada al aula por medio del libro Pomelo es elefantástico. En él se nos propone una forma diferente de entender los afectos, extendiéndolos a objetos, a fenómenos, a plantas, a perfumes, y a diversos personajes. Esta forma permite ampliar el campo de discusión, haciendo factible un mayor número de preguntas y respuestas. Cómo no, lo que amamos y nos ama también nos hace Ser.

Resulta sorprendente cómo los docente pretendemos que los alumnos estén motivados para el conocimiento del mundo, para las matemáticas, la lengua, las ciencias sociales, y sin embargo no nos resulte fundamental la motivación para el autoconocimiento. Da la impresión de que no 
$2^{\text {nd }}$ International Conference Art, Illustration and Visual Culture in Infant and Primary Education
Figuras 3, 4 y 5. A la izquierda: página de Pomelo es elefantástico (capítulo: Pomelo es elefantástico). En el centro: doble página de Pomelo se pregunta (capítulo: Pomelo se pregunta). A la derecha: página de Pomelo es elefantástico (capítulo: Pomelo está enamorado) es conveniente que los alumnos desarrollen la misma sed de aprender, libido sciendi, sobre sí mismos que sobre el resto de cuestiones.
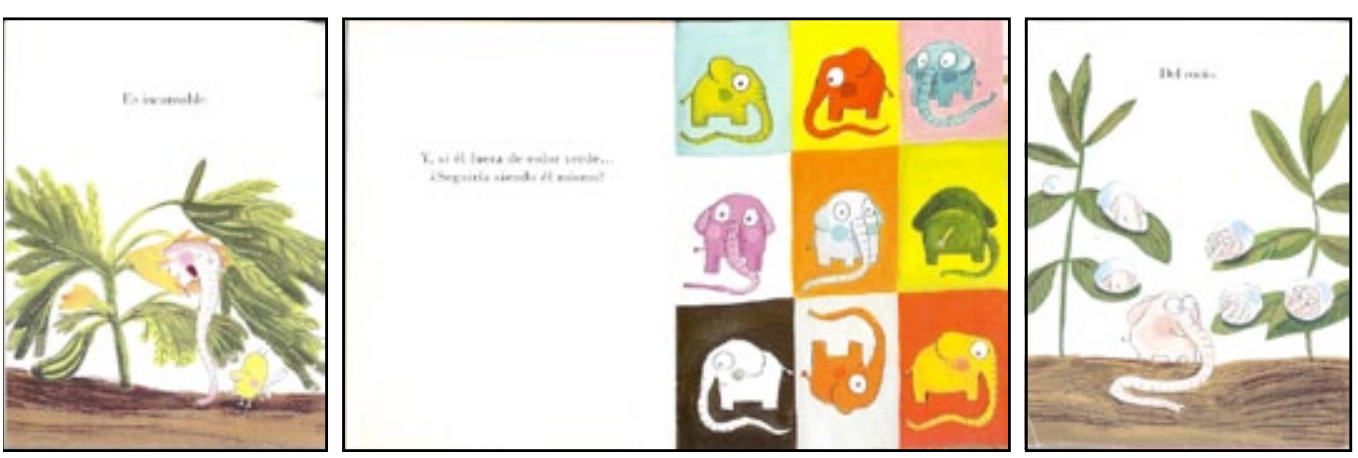

A veces nos escudamos en la falta de tiempo, o en la complejidad de la cuestión. Pero basta mirar a nuestro alrededor para ver que otros no han visto esos obstáculos y nos han tomado ventaja, construyendo una identidad que sirve a sus intereses.

A pesar de la fuerza de esos modelos, no podemos quedarnos impasibles ignorando nuestra responsabilidad. Por mi parte, me sumo a aquellos que postulan que la escuela puede cambiar el mundo. Y qué forma puede haber más efectiva que mediante la construcción de identidades sólidas, tanto individuales como colectivas. Si sabemos que la literatura ha funcionado a lo largo de toda la historia como motor de cambio, si sabemos que estamos inmersos en la era de la imagen, recurrir al álbum ilustrado, que aúna ambas, nos parece que puede ser una decisión acertada.

La meta era la de buscar un nuevo imaginario, con el que cada niño pudiera identificarse de forma particular, pero también que pudiera ser compartido por todos, pues sólo así sería útil para la pedagogía del Ser. ¿Por qué la serie de Pomelo? Porque este elefante es como un niño. Le ocurren cosas normales y corrientes. Demuestra que no es necesario tener superpoderes para ser alguien, que el mejor superpoder es saber quién es uno mismo. Saberlo sin certeza, en un estado de incertidumbre curiosa.

Creo que la metodología aquí propuesta puede lograr el objetivo con el que iniciamos la investigación. El trabajo con las dimensiones ha partido de la lectura y la puesta en marcha de un debate sobre lo leído, con la exposición oral de opiniones y experiencias. Ahora bien, cada docente, al llevarla a su aula, deberá adaptarla a ese contexto, examinando si es necesario otras dimensiones aparte de las comentadas.

\section{Referencias bibliográficas}

Badescu, R. y Chaud, B.

(2005) Pomelo es elefantástico. Editorial Kókinos.

(2005) Pomelo es feliz. Editorial Kókinos.

(2005) Pomelo sueña. Editorial Kókinos.

(2006) Pomelo se pregunta. Editorial Kókinos.

(2008) Pomelo al otro lado del huerto. Editorial Kókinos.

(2010) Pomelo viaja. Editorial Kókinos.

(2011) Pomelo crece. Editorial Kókinos. 
$2^{\text {nd }}$ International Conference Art, lllustration and Visual Culture in Infant and Primary Education $2^{\circ}$ Congreso Internacional Arte, llustración y Cultura Visual en Educación Infantil y Primaria
${ }^{\circ}$ Congresso Internacional

de Arte, llustração e Cultura Visual na Educação Infantil e Primária

Delors, J. (1996). "Los cuatro pilares de la educación." En Informe a la UNESCO de la Comisión Internacional sobre la Educación para el siglo XXI: La educación encierra un tesoro. Madrid: Santillana/UNESCO. Pp. 91-103.

Faure, E. et al. (1973). Aprender a ser. La educación del futuro. Madrid: Alianza Universidad y UNESCO (1978).

Fernández, C. (2008). El aula desierta. Mataró: Ediciones Montesinos.

RTVE: Redes - El sistema educativo es anacrónico. [en línea] Marzo 2011. [Consulta 23 mayo 2012]. Disponible en <http://www.rtve.es/television/20110304/redes-sistema-educativoanacronico/413516.shtml>

TED: Benjamin Zander 2008 Música y Pasión. Con los ojos brillantes. 20 min spanish subtitles [en línea] Febrero 2008. [Consulta 23 mayo 2012]. Disponible en <http://www.youtube.com/ watch?v=71woasL6IQ> 